\title{
La espiritualidad de la alegría: legado del carisma salesiano"
}

\author{
Carmen Sosa Báez ${ }^{* *}$ \\ Rafael González Martín**
}

Recepción: 10 de julio de 2018 • Aprobación: 5 de agosto de 2018

\section{Resumen}

El presente trabajo quiere resaltar la importancia de la espiritualidad de la alegría como el camino por el que se debe avanzar en la vida cristiana para conseguir nuestro verdadero ser cristiano y llevarnos a un estado permanente de felicidad. También dejar claro que cualquier reflexión o propuesta que realicemos sobre la espiritualidad de la alegría ha de tener presente y en cuenta una misión pastoral que favorezca las experiencias de la alegría del Evangelio. Se propone el carisma salesiano como propuesta de santidad desde una alegría profunda en lo cotidiano. Don Bosco repetía constantemente: "Para nosotros la santidad consiste en estar siempre alegres".

Palabras clave: Dios, alegría, felicidad, espiritualidad.

* Artículo de investigación basado en el trabajo de grado titulado La pastoral de la alegría, legado del carisma salesiano: "Estad siempre alegres en el Señor", que fue presentado en el Instituto Superior de Ciencias Religiosas Asidonense. Citar como: Sosa Báez, C. y González Martín, R. (2019). La espiritualidad de la alegría, legado del carisma salesiano. Albertus Magnus, X(2), 119-142. DoI: https://doi.org/10.153322/5005413.5216.

** Instituto Superior de Ciencias Religiosas Asidonense, España. Correo electrónico: carmen.sosa@salesianas.org

*** Centro Concertado de Enseñanza María Auxiliadora, España. Correo electrónico: rafael.gonzalez@salesianas.org 


\title{
The spirituality of joy: Legacy of the Salesian charism
}

\begin{abstract}
The present work wants to highlight the importance of the spirituality of joy, as the way by which we must advance in the Christian life to achieve our true Christian being and bring us to a permanent state of happiness. But also, it is intended to make clear in this work that any reflection or proposal that we make about the spirituality of joy, must take into account and take into account a pastoral mission that promotes the experiences of the joy of the Gospel. The Salesian Charism is suggested as a proposal of holiness from a profound joy in the everyday. Don Bosco constantly repeated: "For us, holiness consists in being always happy."
\end{abstract}

Keywords: God, joy, happiness, spirituality.

\section{A espiritualidade da alegria: legado do carisma salesiano}

\section{Resumo}

O presente trabalho quer destacar a importância da espiritualidade da alegria, como o caminho pelo qual devemos avançar na vida cristã para alcançar nosso verdadeiro ser cristão e nos levar a um estado permanente de felicidade. Mas também, pretende-se deixar claro neste trabalho que qualquer reflexão ou proposta que façamos sobre a espiritualidade da alegria, deve levar em conta e levar em conta uma missão pastoral que promova as experiências da alegria do Evangelho. O carisma salesiano é proposto como proposta de santidade a partir de uma profunda alegria no cotidiano. Dom Bosco repetia constantemente: "Para nós, a santidade consiste em ser sempre feliz".

Palavras-chave: Deus, alegria, felicidade, espiritualidade. 


\section{Introducción}

La espiritualidad de la alegría ha sido un gran desafío en cualquier época, de aquí que estos tiempos de la era de la globalización, de los movimientos migratorios, de los avances tecnológicos y de la comunicación, junto con los grandes cambios generados en el pensamiento humano producidos por factores económicos, sociales, culturales y religiosos que se encuentran en continua evolución, han hecho de la espiritualidad de la alegría una pieza clave de transformación en la vida del cristiano que favorezca las experiencias de la alegría del Evangelio.

Este trabajo quiere resaltar la importancia de la espiritualidad de la alegría como el camino por el que se debe avanzar en la vida cristiana para conseguir nuestro verdadero ser cristiano y llevarnos a un estado permanente de felicidad. La alegría, a pesar de ser temporal, es necesaria como camino para alcanzar la felicidad, ya que no debemos olvidar que en nuestra felicidad encontramos a Dios. También busca dejar claro que cualquier reflexión o propuesta que realicemos sobre la espiritualidad de la alegría ha de tener presente y en cuenta una misión pastoral que favorezca las experiencias de la alegría del Evangelio.

$Y$ es que vivimos en una sociedad que nos informa de todo lo que sucede en cualquier parte del mundo - lo hace casi en tiempo real - en la que reina la tecnología que nos ayuda a adentrarnos en este mundo, tanto el real (en el plano en el que vivimos, nos movemos y existimos) como el virtual (donde puedo crearme un mundo a mi medida y con ello me evado de lo que realmente pasa a mi alrededor).

En nuestro mundo, descubrimos que se da la mayor importancia al individuo y por ello se olvida la llamada que tenemos a vivir en una sociedad y a valorar a los demás en su ser personal, con todos los valores que posee y que me ayudan a crecer como hombre o mujer. Por ello, nos encontramos con personas que para conseguir sus objetivos y proyectos usan a las personas que las rodean; mientras les sean útiles, están con ellas en cuanto que les ayudan y sirven para alcanzar sus objetivos. Así es como nos podemos llegar a convertir en cosas u objetos y con ello olvidamos que somos seres irrepetibles, creados a imagen de Dios.

Es en la realidad que nos toca vivir donde descubrimos que nuestra alegría, la que nos proponen los medios de comunicación social y desde la soledad a causa del individualismo, es efímera y por ello siempre que alcanzamos el objetivo que nos proponemos (tecnología, experiencias - fiestas, voluntariado- trabajo, familia, etc.) tenemos necesidad de buscar nuevos retos o de perseguir objetivos, y si es posible más inalcanzables que los anteriores, porque pensamos que nos darán una felicidad mayor, más duradera. 
Por ello, se hace necesario que la persona, a pesar de la edad que tenga, se pare y se adentre dentro de sí misma, y olvide el ruido y las invitaciones que propone la sociedad. Es necesario que busquemos en el fondo de nuestro propio existir qué es lo que nos puede hacer verdaderamente felices. Los jóvenes y muchos adultos de nuestra sociedad, cansados de buscar la felicidad fuera, en lo que los rodea, en nuevas experiencias, etc., piden que los cristianos les mostremos dónde hemos encontrado esa fuente inagotable de la felicidad que inunda no solo nuestra vida, sino todas las actividades que llevamos entre manos; además, deseamos contagiarla a los que nos rodean y que la vivan.

Con todo lo dicho, este trabajo se estructura en los siguientes apartados. En primer lugar, presentamos un marco teórico que se desarrolla desde las bases conceptuales de los estudios y las investigaciones y literaturas que actualmente existen al respecto de la espiritualidad de la alegría, así como la Palabra de Dios recogida en la Biblia. En segundo lugar, proponemos el carisma salesiano en cuanto propuesta de santidad como una alegría profunda en lo cotidiano, es decir, que, sin importar lo que hagamos, hay que hacerlo con alegría; aun en los momentos difíciles debemos estar alegres porque somos amados por Dios y Él está siempre con nosotros. Don Bosco repetía constantemente: "Para nosotros la santidad consiste en estar siempre alegres". Por último, se concluirá el trabajo haciendo hincapié en que la espiritualidad de la alegría es seguramente la expresión más clara y más fuerte de lo que significa la "humanización de Dios". Lo que pasa es que, con frecuencia, anteponemos nuestra deshumanización a la incomprensible humanidad que se nos reveló en Jesús el Señor. En esto, si no nos equivocamos, radica el fondo del problema.

\section{La alegría y experiencia humana}

La alegría que encontramos en el hombre se produce ante la admiración de lo que le rodea, de lo que puede alcanzar, poseer o tener, y también por los dones que descubre dentro de sí mismo. Toda esta alegría es puesta en el corazón del hombre por Dios, que desea y nos invita a vivir desde esa misma felicidad.

\subsection{Dios, don de la alegría}

Dios, que crea todo lo que nos rodea y lo pone al servicio del hombre, lo hace por puro amor, por ello, ante lo creado muestra que es bueno (Pablo VI, 1975, n. 5), que es portador del amor que Él mismo posee. Todo lo creado tiende a 
Dios, su hacedor. El hombre, creado a imagen de Él, lo puede llegar a descubrir principalmente en la contemplación de la naturaleza y en el encuentro con los que lo rodean. Esto es así porque escucha y descubre la necesidad del otro. Solo saliendo de sí descubre todo lo bueno que el mismo Dios ha puesto en sus propias manos: la posibilidad de ser feliz yendo al encuentro con las criaturas y al encuentro con su Creador (Francisco, 2015, n. 240).

Es el mismo Dios quien pone en el centro de la Creación al hombre y se la entrega para que disfrute de ella, y además pasea junto con él y disfruta de la Creación, lo acompaña a ser feliz. En el diálogo que existe entre Dios y el hombre, se descubre la bondad de que son objeto Adán y Eva. Quiere darles la vida eterna, que requiere por parte del hombre la libre adhesión a la voluntad divina, aspecto que no siempre estamos dispuestos a cumplir por lo que se produce el pecado y junto con él entra la tristeza, ya que no nos adherimos a ella (Léon-Dufour, 1973). Cuando esto sucede, la bondad de Dios se manifiesta en la misericordia y en las promesas de salvación, que unen a Dios y al hombre. Esto es lo que se ve a lo largo de toda la historia del pueblo de Israel, cuando Dios llama y elige a los profetas para que cumplan su voluntad y hagan saber al pueblo que lo ama y cuál es el camino que desea seguir.

\subsection{El hombre llamado a vivir la vida de Dios}

La vida de felicidad y de plenitud de la que nos hace partícipes Dios implica por parte del hombre la libre aceptación de la llamada y la búsqueda de la felicidad que Dios le propone (Catecismo de la Iglesia Católica, 1997). Es el camino de la puerta estrecha $(\mathrm{Mt} 7,13)$, de la que habla el Evangelio, del amor al prójimo y por ello el deseo de buscar el bien para todas las personas. Es también el camino del cuidado de la misma naturaleza, que Dios pone al servicio del hombre, para que la use y disfrute de ella (Francisco, 2015, n. 66). Estamos llamados a vivir como vivió Jesús. Los cristianos, que nos hemos encontrado con Él, sabemos que halló la felicidad en la donación de su vida a los demás y en la confianza en Dios con la que vivió sabiendo que es "dichoso el que confía en Ti" (Sal 84, 13). Los santos, que viven desde el encuentro con Él, son capaces de vivir las dificultades también como momentos que los llevan a la felicidad.

Dios llama al hombre en todo tiempo y lugar. Desde que nos incorporamos, mediante el bautismo a la Iglesia hasta la muerte donde nos encontraremos definitivamente con Él (Catecismo de la Iglesia Católica, 1997). Desea que vivamos siempre en su presencia cada momento de nuestra vida regalando los dones que 
ha puesto en nuestros corazones. Los cristianos que hemos vivido la experiencia del encuentro con Dios sabemos que, a pesar de nuestros errores y fallos, Él nos espera siempre, nos llama siempre, nuevamente, a la felicidad del encuentro con Él. Esta vida de felicidad somos llamados a vivirla en relación con los demás, formando parte de la Iglesia, que nos acoge como el mismo Dios lo hace.

Esta vida a la que Dios nos llama se contrapone a la felicidad que nos ofrece la sociedad tecnológica en la que vivimos, donde lo que más se valora son las cosas que poseemos y las cosas que somos capaces de hacer y llevar a cabo, donde puede llegar a ser más importante el bien propio que el bien que podamos conseguir para un grupo o comunidad de personas, donde comienza a ser más importante el dinero y el poder que pueda alcanzar un individuo que el individuo mismo. Esta alegría es efímera y no nos ayuda a encontrarnos con lo que verdaderamente somos y, por ende, podemos caer en la tristeza, el tedio y la desesperación (Pablo VI, 1975, n. 8).

\section{La alegría en el Antiguo Testamento}

Desde el inicio, Dios establece una alianza con el hombre. Esta alianza, a la que permanece fiel, quiere llevar al hombre a la plena felicidad. Toda alianza conlleva una promesa que ayuda a vivir al hombre desde la fe y la esperanza en que la alianza prometida se cumplirá.

\subsection{La fidelidad a la alianza}

La primera de las ideas que queremos desarrollar la de la alianza, por la por el que el mismo Dios, por puro amor hacia el hombre creado a su imagen y semejanza, quiere llevarlo a la plena felicidad y lo llama a vivir desde la alegría. Dios desea que el hombre viva en comunión con Él (Léon-Dufour, 1973). Cuando hablamos de alianza, debemos entender aquel pacto que se da desde antiguo en todas las civilizaciones; el trasfondo de las alianzas es prestar y recibir la ayuda necesaria, podríamos decir que es un pacto de vasallaje, por el que la parte débil pide ayuda a otra parte que es más fuerte y puede, si así lo desea, ayudarlo. La ayuda conlleva unas cláusulas que debe cumplir el que pide la ayuda. Por ello, encontramos que las alianzas son, desde establecer una amistad, hasta las que se dan en caso de guerra, pasando por el matrimonio (Pablo VI, 1975, n. 8).

Las alianzas tienen un rito por el que se firman o establecen, y testigos que recuerden las alianzas firmadas y las repercusiones en el caso de no respetarlas 
(Pablo VI, 1975, n. 8). Lo encontramos también en la alianza que Dios establece con Abraham cuando le confirma que tendrá una descendencia como las estrellas del cielo y que esta saldrá de su hijo, que concebirá Sara, su mujer. Él pregunta cómo sabrá que es cierta la promesa y Dios le pide que lleve una serie de animales para firmar el pacto y allí Abraham erige un altar para recordar la alianza hecha con Dios (Gn 15, 17-21). Encontramos que el pueblo de Israel establece alianzas de vasallaje, pero también reconoce que Dios, desde la gratuidad, quiere establecer con ellos una alianza.

La alianza más importante para el pueblo de Israel es la que se establece en el monte Sinaí, el intermediario entre el pueblo y Dios es Moisés, llamado por Dios a liberar a su pueblo que clama desde Egipto. La alianza queda establecida por varios objetos que atestiguan el compromiso de Israel: el arca en el que se depositan las tablas de la Ley sirve de memorial de la alianza y de la presencia de Dios en medio del pueblo, y la tienda del encuentro que será el esbozo del templo como lugar de encuentro entre Yavhé y su pueblo.

Toda alianza pide al Pueblo de Dios fidelidad, que a su vez implica la fe en que lo que se ha prometido se cumplirá. Fidelidad que el hombre abandona en el momento en que aparecen las dificultades o en que los caminos que indica Dios no coinciden con aquellos que el mismo hombre quiere recorrer. Encontramos el ejemplo más sencillo en el desierto, una vez han sido liberados de la esclavitud de Egipto, cuando Moisés ha subido al monte Sinaí para encontrarse con Dios. El pueblo, al ver que tarda en volver, crea un dios en forma de becerro de oro (Ex 32). Cuando murmuran contra Dios y Moisés porque creen que morirán de hambre y sed en medio del desierto (Ex 16). Es un pueblo cuya fe y fidelidad se han de ir purificando y cuya esperanza se enraíza en los beneficios terrenos. La alianza de Dios con su pueblo también es actual en nuestra sociedad. Cada uno de nosotros está llamado a vivir desde el gozo que viene de seguir los mandatos de Dios, de escuchar su Palabra y hacerla vida desde nuestra propia existencia.

\subsection{Una promesa que sostiene la esperanza}

La alianza que Dios establece con su Pueblo de que le dará la tierra prometida a sus padres lleva implícita la promesa de que a su tiempo Dios cumplirá al Pueblo lo que ha dicho. Promesa que se revela poco a poco y que no será una realidad terrena, sino que será en la vida eterna donde seremos semejantes a Él. La promesa pide del hombre fe y confianza que lo lleven a apoyarse en Dios, y esperanza, que se enraíza en la primera y lo lanza hacia su vivir como creyente (Léon-Dufour, 1973). 
La promesa hecha a Abraham de una tierra y una descendencia numerosa permanece en el pueblo que lee su propia historia y descubre que los dones que reciben son fruto de vivir la alianza hecha, y se vive la dicha y la alegría. Los profetas son enviados por Dios a recordar a su Pueblo que deben vivir desde la alianza, denuncian las injusticias que comete el Pueblo y lo llaman a vivir la conversión en los momentos en los que la abandonan, siguiendo a los pueblos paganos. Con la conversión, son llamados a optar por el camino de la alegría, la esperanza y la confianza.

Los profetas enseñan al Pueblo de Israel que Dios está siempre esperando la vuelta a su alianza. Cuando se ha abandonado el pacto, Dios celebra con alegría la vuelta del pueblo que lo busca con todo el corazón, de la persona que quiere vivir desde la promesa realizada. Así también lo presenta el mismo Jesús cuando narra las parábolas de la misericordia y afirma que hay más alegría en el cielo por un pecador que se convierte que por noventa y nueve justos que no necesitan convertirse (Lc 15, 7). Dios cuenta, al realizar la promesa, que quiere un pueblo libre, no esclavo, como podría pasar con los dioses extranjeros. Quiere que el pueblo y la persona escojan vivir la alianza desde la libertad. Es el profeta el encargado de recordar que vivir la alianza es estar en el camino del gozo y de la alegría perpetua.

El profeta es el encargado de ayudar al pueblo a esperar mirando hacia el futuro. Es un hombre que vive y se fundamenta en el pasado, de gran importancia para el pueblo. Así se presenta cómo Dios va actuando a lo largo de la historia, desde la lectura que es Dios el que lleva la historia del hombre, desde donde se vive en la esperanza del cumplimiento de la promesa. Por ello, el hombre debe confiar en el mismo Dios que lo llama y no en sus propias fuerzas o en las falsas seguridades que le dan los poderosos de la Tierra. Finalmente, se debe señalar que el mismo profeta, que siente arder en su entraña la Palabra que Dios le dirige, siente que ella es su gozo y alegría, a pesar de la no aceptación por parte del pueblo al que llama a la conversión, a volver, como ya hemos dicho, a la alianza. Prefiere las seguridades del presente que las promesas que se realizarán en el futuro.

\section{La alegría en el Nuevo Testamento: Cristo}

Jesús, anunciado ya por los profetas, es la promesa de Dios enviada a la Tierra para que vivamos desde la alegría la alianza que también desde antiguo ha hecho. Él nos muestra el camino hacia Dios que, como se muestra en el Antiguo Testamento, es el que nos lleva a una vida plena, no sin caídas y dificultades. 


\subsection{Jesús es la Buena Noticia anunciada}

En los evangelios de Marcos y Lucas, en textos de la infancia, encontramos el anuncio del nacimiento de Jesús, la Buena Noticia, el culmen de la promesa de Dios hecha a su Pueblo. La primera persona que recibe el anuncio de la Buena Noticia, y con ello la alegría de la que es portadora, es María, cuando el ángel Gabriel en el saludo le dice: "Alégrate, llena de gracia", y después le anuncia que será la madre de Dios (Lc 1, 26-38). Antes del anuncio a María, sabemos que Zacarías recibe la visita del ángel que le hace saber que sus oraciones han sido escuchadas y que en la vejez será padre. Le revela el nombre que recibirá. Nacimiento que le llenará de alegría y que alegrará a muchos (Lc 1, 14). Zacarías, después del nacimiento de su hijo, exulta, lleno del Espíritu Santo, las maravillas que Dios ha hecho. Canta un cántico porque Dios ha visitado a su pueblo (Lc 1, 68-79; Bravo, 2012, pp. 41-42).

María, llena del Espíritu y de la alegría recibida, va a visitar a su prima Isabel porque la alegría que siente debe ser compartida. En el encuentro, el que salta de gozo y se llena del Espíritu Santo es el precursor del Mesías, Juan. Es María quien canta las maravillas que Dios hace a los pobres y a quienes guarda su alianza (Lc 1, 39-56). Encontramos que también José, tras conocer que María espera un hijo, recibe la visita de un ángel, que devuelve la alegría a su vida, pues comprende lo que ha sucedido a su futura esposa y por ello la acoge en su casa (Mt 1, 18-25). Esta noticia, la del nacimiento del Mesías, se anuncia a todas las naciones. Por esta razón, un ángel visita a los pastores y les anuncia que cerca de allí ha nacido el Salvador. Creen el anuncio y van corriendo a ver lo que ha sucedido, y después de ver, vuelven cantando y bendiciendo a Dios (Lc 2, 8-20). Sabemos que los pastores no participaban de la religión judía, por ello desde las periferias llega el anuncio a todas las naciones de la Tierra (Bravo, 2012, pp. 39-40).

Para reforzar que la Buena Noticia es para todos, y no solo para el Pueblo de Israel, también se alegran los magos que visitan a Jesús y le ofrecen oro, incienso y mirra, lo que señala de forma nueva que la salvación es para toda la humanidad (Bravo, 2012, pp. 39-40). Ellos vuelven por otros caminos llenos de alegría por haber encontrado al Rey que salvará al mundo (Mt 2, 1-12). Cuando Jesús es presentado en el Templo, siguiendo la tradición, es bendecido y llena de alegría a todos los que esperan en las promesas de Dios. Así lo proclaman Simeón y la profetisa Ana (Lc 2, 25-38). Ellos también señalan la alegría porque Dios visita al pueblo y cumple la promesa realizada a sus antepasados. Nosotros sabemos que Jesús es la verdadera alegría para los pobres, los excluidos, los marginados, y todos aquellos que quieran ser sus discípulos. 


\subsection{Jesús goza con la alegría, la que nos lleva a Dios}

Jesús experimenta en su vida, como hombre que es, las alegrías que todos podemos experimentar a lo largo de nuestra vida. Se fija en las cosas sencillas de la creación que nos llevan al Creador: los pájaros y las flores. Goza con el sembrador, con el hombre que encuentra un tesoro escondido, con el pastor que encuentra a la oveja perdida, con la mujer que da a luz, con las bodas. Todas ellas son las que hacen que construyamos el Reino de Dios en la Tierra, que seamos acogidos por el Padre (Pablo VI, 1975, n. 23).

Lo que le produce mayor alegría a Jesús es la acogida de su palabra, el cambio de vida que produce en quien lo escucha. Sobre todo en los pecadores: publicanos, poseídos, enfermos (Pablo VI, 1975, n. 23). Queremos señalar cómo Jesús, tras el encuentro con algunas personas, cambia su vida, cómo surge la alegría tras el diálogo con ellos. Son rasgos que nos ayudan a hacer presente y vivir el Reino de Dios que predica Jesús durante su vida pública. La primera que deseamos reseñar es la samaritana; en el encuentro, no se habla de forma explícita de la alegría, pero sí que vemos cómo la samaritana deja el cántaro y va al pueblo a anunciar lo que le ha pasado. Ese dejar todo, el cántaro, que era lo que le daba vida, nace de la alegría.

Otro encuentro que cambia la vida es el encuentro con Zaqueo, que acoge la invitación de Jesús para comer en su casa. Tras la comida, Zaqueo descubre que la verdadera felicidad, y con ella la alegría, no está en las cosas materiales, sino en seguir a Jesús. También el ciego Bartimeo deja todo lo que tiene, su manto, para acercarse a Jesús y quedar curado. En la curación de los enfermos, queda claro que en Jesús se cumplen las profecías dichas por los profetas (Is 61, 1-3). Jesús sabe que no todos lo acogerán; por ello, aparece la murmuración, que es lo contrario de la alegría y de la acogida.

También Jesús se da a conocer y presta su ayuda en las bodas de Caná. En el mundo judío, la boda ya es un símbolo de alianza y de alegría; en el texto que estamos describiendo, es una alianza con todas las naciones, como ya hemos señalado. La alegría que llena la vida de Jesús es la de saberse hijo de Dios. Es la alegría que procede del Padre, una alegría, como ya hemos expresado, que se alegra con la vuelta del hombre a Dios, a la vida que Él le ofrece. En Jesús, encontramos que es una alegría que está animada por el Espíritu Santo, que recibe en el bautismo de una forma desmedida. Es la alegría que inunda su vida y que le lleva a vivir tanto los momentos difíciles como los gozosos, la que lleva a dar gracias al Padre por revelarse a los sencillos y pequeños (Bravo, 2012, p. 63). La alegría que nace 
del Espíritu es la que nos lleva a una confianza plena en el Padre y a buscar el Reino, porque todo lo demás se nos concederá por añadidura (Lc 12, 31; Bravo, 2012, p. 63).

\subsection{Jesús entrega su vida para que nuestra alegría llegue a plenitud}

Jesús, al realizar la voluntad del Padre, en su disponibilidad, entrega su propia vida, porque sabe que la recobrará (Jn 10, 17); por ello, su entrega es desde la alegría (Pablo VI, 1975, n. 24). Esa alegría, cuando entrega la humanidad en la cruz, nace al ver cómo los hombres (los pobres, los enfermos, los excluidos, etc.) acogen su palabra y cambian sus vidas reconciliándose con el Padre. Dios se hace presente en la vida de las personas y con Él la salvación del hombre (Bravo, 2012, p. 62). Esta entrega por amor la encontramos como esencia dentro de la Trinidad, ya que el Padre da al Hijo de forma generosa a la humanidad para que pueda conocer al Padre, y el Hijo se entrega al Padre de la misma manera en el Espíritu (Pablo VI, 1975, n. 24). La comunión trinitaria es la alegría perfecta. Se da la donación del Padre y del Hijo en el Espíritu (Bravo, 2012, p. 66).

Jesús vive desde su alegría de ser Hijo la lucha de la obediencia, en la que se encuentran enfrentadas la voluntad divina y la humana, asumir el camino del sufrimiento, de la obediencia al Padre, y evitar vivir la alegría del camino efímero del gozo (Bravo, 2012, p. 67). Esa obediencia la vive Jesús desde la alegría de que la muerte no es el final del camino, sino la vida, la resurrección (p. 68). En los relatos de las apariciones del resucitado, vemos cómo surge en aquellos hombres una alegría permanente. La alegría que surge en los discípulos tras la muerte de aquel que era su esperanza y en quien habían puesto toda su confianza.

Así podemos señalar el encuentro de María Magdalena con el resucitado que busca a su Señor con el que vivió. Su llanto se torna en alegría cuando es llamada por su nombre, su vida se transforma, y tras el encuentro, es enviada a proclamar lo que ha visto y el mensaje de Jesús: que vayan a Galilea, que allí lo verán. Pero no es el único caso, podemos señalar aquel en el que estaban todos reunidos en el cenáculo y se les presenta Jesús. Ante la sorpresa y no terminar de creerse que era Él, les pide un poco de comida. Es una alegría que transforma de una forma profunda la vida de quien se encuentra con Él, que le lleva a darlo a conocer, a transmitir lo que se ha visto y oído, a proclamar que es Jesús el que nos salva y que muere por nuestros pecados. 


\section{La alegría en la vida de la Iglesia}

La alegría cristiana no se puede pensar, ni tan siquiera vivir fuera de la Iglesia, no tanto como institución, sino como vida que se da dentro de la comunidad cristiana, en la que nos sirven de ejemplo las primeras comunidades cristianas: "perseveraban en la enseñanza de los apóstoles, en la comunión, en la fracción del pan y en las oraciones" (Hch 2, 42).

\subsection{El mandato de evangelizar}

Después de la alegría de la resurrección de Jesús que invade a los Apóstoles, nace en ellos, como en todos los que se encuentran con Jesús, la necesidad de darlo a conocer, de evangelizar. Por ello, salen fuera de sus casas a proclamar lo que han visto y oído, lo que han vivido junto a Jesús. Para las comunidades cristianas, es hoy también una llamada a salir fuera de los propios espacios y proclamar a los que viven en las calles, de donde nace la propia felicidad (Francisco, 2013, n. 20). Es preciso recordar que el mandato o envío a evangelizar es para todos los bautizados y que somos llamados a evangelizar a todos los hombres. Bien es verdad que nos encontramos que hay cristianos que por diversas causas se han alejado de la Iglesia y no cumplen sus mandatos, otros que ni tan siquiera han escuchado hablar de Jesús y los que viven dentro de las comunidades y también necesitan profundizar, mediante la formación permanente, en su propia vida de fe (Francisco, 2013, n. 14-15).

Cuando hablamos de evangelizar, nos referimos a sembrar la semilla de la Palabra, que es eficaz y supera todas nuestras expectativas y pensamientos (Francisco, 2013, n. 22). Sin embargo, es importante cuidar, en la actualidad, la transmisión de la Palabra que ayude al encuentro con Jesús, quien nos llena de alegría (n. 34). Necesitamos recordar que, actualmente, en la evangelización lo que debe cambiar es el lenguaje que usamos para dar a conocer el mensaje. Como ejemplo, sirva que Jesús habló en parábolas. Lo que no puede variar es el mensaje que nos lleva a la salvación: Jesús entrega su vida por todos los hombres para el perdón de los pecados (n. 36). Esa entrega por amor a los demás es la que nos invita a cada uno de nosotros a amar a los hermanos, un amor gratuito que hemos recibido de Dios, que nos llena de gozo y nos acerca más a nuestro Hacedor.

Cuando transmitimos el mensaje, según Francisco, debemos tener presente también las costumbres de los lugares donde nos encontremos. Es importante que esas costumbres respondan a lo fundamental de la fe que vivimos y no se 
conviertan en cargas para aquellos que deben ponerlas en práctica (Francisco, 2013, n. 43). La evangelización a la que se invita hoy a la Iglesia tiene que partir de la realidad en la que nos encontramos, de las situaciones de las personas, y contar con la cultura en la que vivimos. Ese proceso de inculturación que se viene haciendo desde el comienzo del cristianismo no tiene un proceso definido; al contrario, es distinto en cada realidad (n. 129). El cristiano debe ser como la sal y la luz en medio del mundo: con su propio ejemplo transparenta la vida a la que el mismo Dios lo llama.

El evangelizador o agente de pastoral debe tener presente que está en el mundo pero no es del mundo $(\mathrm{Jn} 17,16) \mathrm{y}$, por ello, tiene que tener presentes las tentaciones de las que habla Francisco (2013, n. 76-86) y que nos alejan o evitan que vivamos la alegría del encuentro. La primera de las tentaciones en la que podemos caer todos aquellos que deseamos anunciar lo que hemos experimentado en el encuentro con Jesús es la de cuidar los espacios personales, espacios donde cuidamos nuestro tiempo libre, tiempo en el que no anunciamos la Palabra porque estamos pendientes de nosotros mismos.

Otra tentación en la que podemos caer es realizar las actividades pastorales sin cuidar nuestra espiritualidad, actividades que llevamos a cabo desde el propio voluntarismo, desde las propias fuerzas y, quizá, no desde el envío del mismo Jesús que nos llama. Una última tentación nos lleva a no descubrir todo lo bueno que hay en el mundo actual, en la sociedad en la que vivimos, que, a pesar de los contravalores que transmite, tiene mucho de bueno, que debemos aprovechar para llegar a aquellas personas que se encuentran más alejadas de la Iglesia.

Es fundamental en el proceso de evangelización la formación de todos los cristianos. Debe ser una formación que abarque toda la vida, desde la infancia hasta la ancianidad (Francisco, 2013, n. 120-121). Cada edad tiene un proceso, un itinerario para ir creciendo y profundizando la fe, mas no debemos olvidar que nuestra fe tiene como fundamento la entrega del mismo Jesús por la salvación de cada hombre y el mandamiento de amar al prójimo como a uno mismo (n. 160162). Solo podremos entregar a los demás aquello que vivimos.

\subsection{La vida desde la comunión}

La evangelización de la que hemos hablado tiene como fundamento vivir la comunión, vivir en comunidad. Estamos llamados a vivir en sociedad y, por ello, también en comunidad debemos crecer en el seguimiento de aquel que nos llama. Entendemos que vivir en comunidad es poner lo que somos (cualidades y 
dones recibidos del Señor) y poseemos en común, ponerlo a disposición de las personas con las que se comparten todos los acontecimientos y las experiencias que vivimos. Ese vivir juntos puede realizarse de dos formas: la primera de ellas es formar parte de una comunidad cristiana o grupo con una espiritualidad concreta inserta en una parroquia y la otra es la forma de vida de las comunidades religiosas en las que se vive en común.

Un aspecto común en ambas es que las personas que allí se reúnen son convocadas por el mismo Señor (Bravo, 2012, pp. 162-165), que mediante su Espíritu nos invita a servir y hacer crecer nuestra fe junto a los demás. En toda comunidad, para que crezcan la fe, la esperanza y la caridad, es necesario que haya una persona que guíe, un pastor que vele por los miembros de la comunidad, principalmente por la formación, y llevarla a la vida, donde podemos descubrir los caminos por los que quiere Dios que vayamos avanzando, y también descubrir juntos los aspectos de nuestra vida y de la misma sociedad en la que nos encontramos, que son los "lobos" que destruyen la comunión.

La vida en común tiene un gran reto: las relaciones interpersonales. Es en ellas en las que debemos recordar que nos llama el Señor. Es Él quien nos une y quiere que caminemos juntos (Francisco, 2013, n. 113). Este campo es aquel en el que las comunidades cristianas y también las religiosas encuentran sus mayores problemas, pues cada una de las personas queremos y creemos que nuestras opciones, opiniones y formas de ver las cosas son las mejores. Es necesario realizar un camino donde crezcamos en la asertividad, en la acogida del otro tal y como es, en estar dispuesto a dar a los demás los dones que el Señor nos ha dado, en ampliar la mirada - mirando más allá de nuestros pensamientos - y descubrir que juntos podemos encontrar el camino y la mejor forma de llevar el Evangelio a todas las personas con las que nos encontremos en la vida.

La Iglesia, como comunidad de personas reunidas en el nombre de Jesús, tiene que presentarse como signo de salvación a los hombres (Francisco, 2013, n. 112). Por ello, la vida de la comunidad cristiana debe ser ejemplo al vivir los valores del Evangelio no solo de palabra sino con las obras que realiza. Así es como nos convertimos en testimonio e interrogamos a los que nos ven y pueden decir que se nos conoce por el amor que mostramos unos a otros (Jn 13, 35).

\section{Una pastoral de la alegría}

La pastoral, en estos años, ha tomado una gran importancia, pues vamos descubriendo la necesidad de llegar a las personas, de transmitir lo que hemos visto 
y oído (1 Jn 1, 3). Cada uno de los cristianos estamos llamados a vivir las claves pastorales que a lo largo de su pontificado nos propone Francisco (Gutiérrez y Rojano, 2016).

La primera de las claves es la proclamación de la Palabra, dar a conocer a la persona de Jesús, y para ello es necesario transmitir el Evangelio. Solo desde el conocimiento y el encuentro con Jesús damos lo mejor de nosotros mismos y superamos las dificultades que en la vida se nos presentan. Cuando presentamos a Jesús, nos damos cuenta de la importancia que tienen los pobres, los marginados y los enfermos en su misión. Cada uno de nosotros somos llamados a descubrir a Dios en ellos. Acercarnos a los pobres nos lleva a una tercera clave que es vivir la misericordia. Llevar a cada persona la ternura y la bondad que cada uno hemos recibido del mismo Dios.

La cuarta es el discernimiento, entendiendo que quien vive esta actitud es sensible al Espíritu y reconoce con humildad quién es, sus propios límites y se pone en camino para cambiar. Los cristianos debemos aprehender que la conversión es una actitud que nos acompaña toda la vida. Y es esta necesidad de cambiar la quinta de las actitudes pastorales, podríamos señalar también que es la necesidad de conversión que nos lleva a vivir menos egoístamente, porque dejamos de vivir pendientes solo de nosotros y más centrados en Cristo, y ello nos lleva a vivir más atentos a las personas que nos rodean.

Otra de las actitudes que nos invita a vivir Francisco es caminar juntos, formar comunidad, ponernos de acuerdo y buscar siempre el bien común en el lugar en el que estemos. Y, finalmente, somos llamados a vivir el cuidado de la naturaleza, el cuidado del prójimo, el cuidado de las familias. Esta actitud tiene que ver con la anterior, porque nos pide pensar en el otro antes que en uno mismo. Todas son actitudes que debemos tener presentes en nuestra acción pastoral, cualquiera que sea e independientemente del lugar en el que la llevamos a cabo.

\subsection{La alegría en la familia}

No podemos hablar de la alegría y la vida de fe de la familia sin presentar la realidad que esta vive, sobre todo en los países más desarrollados. Todos conocemos cómo dentro de las familias actualmente se deben cuidar las relaciones. En primer lugar, se dan dentro del matrimonio (quizá podemos señalar que empiezan desde el noviazgo), debe ser una relación en la que se dé el diálogo, el conocimiento mutuo, y una relación que debe ir superando las dificultades (Francisco, 2016, n. 41) que se dan en el momento en el que dos personas sueñan con un proyecto 
en común. Ese diálogo que ocurre entre el matrimonio crecerá con la relación con los hijos fruto del mutuo amor.

Debe ser una relación que ayude desde la humildad a descubrir a Dios en el otro y a ver la vida desde lo positivo. A mirar con esperanza la construcción de ese sueño que une al hombre y a la mujer en matrimonio. Pero, en muchas parejas, ese sueño común poco a poco va muriendo y por ello desapareciendo hasta que llega a reinar el individualismo tan presente en la sociedad que rompe la relación y la unión que entre ellos existe. El matrimonio pasa a ser entonces el lugar en el que se sacian las propias necesidades y no el lugar en el que se crece y se vive (Francisco, 2016, n. 34).

Cuando queremos evangelizar a las familias, debemos cuidar los momentos en los que vienen, motivados por la fe que tienen y por la tradición recibida de sus padres. El primer momento, en el que se acercan a la Iglesia la mayoría de las familias, ocurre cuando desean que sus hijos reciban el sacramento del bautismo (pero también pasa con la primera comunión). Desean que entren a formar parte de la Iglesia, aunque no siempre vivan esa fe. Pues es el momento de acompañarlos y, quizá, mostrarles que la vida de la Iglesia, como en las primeras comunidades, está llena de vida y se alegra por cada uno de sus hijos.

Sería bueno que se sintieran invitados y acompañados por algún miembro de la comunidad cristiana en la experiencia que tienen del sacramento de la reconciliación y de la eucaristía. En ambos, la Iglesia encuentra la alegría y la fuerza para recorrer el camino de la vida, con sus alegrías y sus tristezas. Es importante, y quizá el primer paso en esta pastoral con las familias, la escucha por parte de la comunidad o de uno de sus miembros; escucha de su situación (personal, familiar, laboral, etc.), de lo que viven, de lo que llena su corazón (Francisco, 2016, n. 128). Un momento de escucha en el que debe, si es adecuado, presentar la Palabra de Dios, dar a conocer el amor que Dios nos tiene por ser sus hijos.

Es un acompañamiento que debe ser realizado por sacerdotes, diáconos o seglares que se hayan preparado en este camino de ponerse al lado de otras familias y ayudarles a descubrir lo que Dios quiere de cada una de ellas (Francisco, 2016, n. 169). Acompañamiento que debe acercar a la persona a Dios y no debe quedarse en la persona misma pudiendo producirse un encierro en sí (n. 170), que debe respetar los ritmos y caminos que la persona quiere recorrer (siempre dentro de la fe y que ayuden a vivir); es un acompañamiento que debe llevar a descubrir la libertad.

Cuando deseamos que las familias se incorporen a la vida eclesial, podemos también proponerles pequeños proyectos en los que las personas que invitamos 
se sientan cómodas, y además descubran, en algún momento, sus propios dones y carismas. Como ejemplo sirva presentar la labor de Cáritas y cómo prestando un servicio de voluntariado se puede colaborar desde ayudar a organizar alimentos, ropa o buscar las cosas que necesiten otros, pero también hay lugares en los que los matrimonios pueden colaborar enseñando español o ayudando a familias inmigrantes en tareas como la compra. Pienso que desde las comunidades parroquiales se debe invitar a los matrimonios a prestar algún servicio que entre dentro de sus posibilidades, pero lo más importante es irlos formando, que se interroguen sobre su forma de vivir, de afrontar las situaciones de la vida.

\subsection{La alegría en la ancianidad}

Cuando hablamos de la familia, debemos tener presentes a nuestros mayores, a los más ancianos y, quizá, enfermos. Ellos son los que nos han ayudado a ser lo que somos y los que transmiten la cultura y las tradiciones que hemos recibido. En la sociedad en la que nos encontramos, pueden llegar a ser una carga (Francisco, 2016, n. 48), esto es así pues en la sociedad actual trabajan en las familias ambos cónyuges, y no hay tiempo para dedicar a las personas que ya por la edad que tienen necesitan ayuda de una forma continua o están enfermos. Pero sí que encontramos que son los que se hacen cargo en muchos casos de sus nietos. Son los que los recogen del centro escolar, los encargados de llevarlos a las actividades extraescolares y, en no pocos casos, de darles de cenar y ocuparse de ellos hasta la noche, que llegan sus padres al finalizar su trabajo.

Lo que sí es cierto es que ellos - nuestros mayores - son los que en la mayoría de los casos transmiten en la actualidad a sus nietos las primeras nociones cristianas (Francisco, 2016, n. 192), es decir, les enseñan la señal de la cruz y las primeras oraciones. Son los que en muchos casos acompañan a los niños durante el periodo de catequesis a la celebración de la eucaristía. Así que son, en muchos casos, los transmisores de fe. En la sociedad en la que nos encontramos, debemos crecer en la alegría de percibir la grandeza de contar con la sabiduría de la vida, adquirida por nuestros mayores. Debemos recoger el testigo de lo que ellos nos transmiten para que nuestro mundo siga avanzando (n. 192-193), siga creciendo en aquellos valores que se convierten en fundamentales, sobre todo el valor de la vida en todas sus etapas (n. 48). Aquí nos encontramos con dos prácticas (eutanasia y suicidio asistido) que, a pesar de ser legales en muchos países, van contra este valor tan importante. 


\subsection{La alegría para los niños y jóvenes}

Los niños y los jóvenes son fuente de alegría desde su propio ser, que, a pesar de las dificultades (entre ellas, las separaciones de sus padres y los nuevos estilos de familias, el individualismo, la indiferencia, la superficialidad, la falta de compromiso social y la crisis de pertenencia a las instituciones con las que se encuentran), son capaces, en el momento en que se sienten escuchados y queridos, de mostrar y regalar su alegría (Centro Nacional Salesiano de Pastoral Juvenil, 2014, pp. 37-42).

Como también hemos indicado, en las familias las dificultades no siempre ayudan en el crecimiento y en la maduración de los niños y jóvenes. Por ello, se hace necesario en la actualidad seguir ayudando tanto a los más pequeños como a los jóvenes, pasando por los adolescentes, a crecer en ser "buenos cristianos y honrados ciudadanos". Así lo hizo Don Bosco en su tiempo, en medio de las dificultades de su época. Cada uno de los miembros de la familia salesiana estamos llamados a actualizar el sistema preventivo y llegar a los niños y jóvenes de hoy, y ayudarlos en sus dificultades (Moral de la Parte, 2014, pp. 49-57).

Este crecimiento nos invita, en primer lugar, a releer nuestro actuar; en este caso, podríamos decir, nuestra evangelización, lo que nos invita a partir de la experiencia del joven. Es para ello fundamental la escucha atenta de aquellas cuestiones que interesan o inquietan a la persona que se acerca a nosotros, los educadores (Francisco, 2013, n. 128). Solo desde el diálogo y la acogida incondicional, que invita con el tiempo a la confianza, podremos llegar al corazón del niño, joven o adolescente, e invitarlo a vivir la vida que Jesús nos invita. En muchos momentos, tendremos que invitar al joven a cambiar su forma de actuar y pensar, pero la persona que se siente acogida por otra tal y como es puede comprender la necesidad de cambiar y llevarlo a cabo siempre que vea en ello un bien para su propia vida y para la de los que lo rodean (Moral de la Parte, 2014, pp. 49-57).

Nuestro ejemplo, nuestro estar y nuestro escuchar y acompañar serán, para el niño o el joven, una cuestión, se preguntarán la razón de nuestro actuar, de nuestro donarnos cuando en muchos momentos lo que viven alrededor es pensar más en uno mismo que en los demás. Otro aspecto que debemos cuidar, mejorar y hasta adaptar a los nuevos tiempos es la propia transmisión de la fe. Esta transmisión no debe quedarse solo en su aspecto doctrinal, sino que debemos ir más allá y enseñar la importancia del amor a todos, como lo hizo Jesús con sus discípulos en la última cena (Francisco, 2013, n. 161).

Tenemos que ayudar a nuestros niños y jóvenes a crecer en todos los aspectos de su vida. Por ello, si deseamos que aprendan un oficio, y para ello van a 
los colegios y a las universidades, debemos también ayudarles a crecer en la fe, y es aquí donde encontramos la importancia de la catequesis. Esta debe ayudar a quien la recibe a sentir, y no solo a saber, que Dios lo ama; estas palabras son el mensaje principal que todo cristiano debe escuchar (Francisco, 2013, n. 164). Cuando la persona se siente amada por Dios y por la comunidad cristiana, puede acoger toda la doctrina que se le quiere transmitir, puede comprender e integrar en su vida lo que la Iglesia vive y le pide que viva (n. 165). Otro aspecto importante es la progresividad en la transmisión de la fe y usar, para llegar a nuestros destinatarios, aspectos en los que se toque la sensibilidad de la persona como la belleza que los rodea (n. 166-167). Por último, debemos presentar la moral cristiana desde lo positivo y no como normas que se nos imponen o debemos cumplir para ser mejores personas (n. 168).

No debemos olvidar que en la transmisión de la fe debemos respetar la libertad de la persona; esto es importante, lo mismo que educar a los niños y jóvenes en la libertad. Muchos piensan que la libertad es hacer lo que les gusta o desean, y deben comprender y aprender que en un primer momento nuestros actos tienen consecuencias, y que mi libertad no debe atentar contra los demás que conviven conmigo. Por último, tenemos que volver a educar a los más pequeños de nuestra sociedad en la vida sacramental, tenemos que ayudarlos a descubrir y vivir los sacramentos como más que una obligación o un cumplimiento. Tenemos que ayudar a los más jóvenes de nuestra Iglesia a descubrir la importancia de celebrar los sacramentos, integrar en la propia existencia que aquello que se celebra nos ayuda a crecer en la fe y que es necesario vivir y participar juntos en comunidad.

\subsection{La alegría para los descartados}

Nuestra pastoral debe tener en cuenta también a los pobres, a los de nuestro entorno y a los que nos quedan más lejos, a los que están en esos países que viven sumidos en ella. Esta pastoral es una opción preferencial en la Iglesia (Francisco, 2013, n. 186), pues el mismo Jesús nace y vive pobre, y además dedica su vida a los pobres de su sociedad. La pobreza con mucha frecuencia es material, falta lo necesario para llevar una vida normalizada, una vida en la que se cumplan los derechos básicos de todo hombre: poder tener una vivienda, alimentación, sanidad, educación, entre otros. Aunque en nuestra sociedad también podemos encontrar una pobreza en valores. No podemos sentirnos privilegiados por haber nacido en un país y en una familia en los que podemos tener todo aquello que necesitemos. 
Nuestra misión como Iglesia debe ser buscar los medios para que las estructuras sociales que favorecen el enriquecimiento de unos y el empobrecimiento de otros cambien (Francisco, 2013, n. 188); es una tendencia a nivel mundial ver cómo los pobres con el tiempo lo son más y al contrario los ricos también aumentan sus riquezas. Es cierto que las estructuras sociales que no favorecen la igualdad tienen como base la economía. Como respuesta a la pobreza material, surge la solidaridad, entendiendo por ella que aquello que se posee debe ponerse al servicio de los más necesitados (Francisco, 2013, n. 189). Es una llamada no tanto a dar lo que me sobra o no necesito, sino a dar lo que tengo y que puedo compartir. No basta con nuestra ayuda asistencial (dar comida o ropa) de manera puntual, pues soluciona un problema en el momento presente pero no ayuda a las personas a conseguir un futuro mejor, a solucionar esos problemas que los hacen vivir marginados dentro de la sociedad.

Tenemos que ayudarlos a conseguir una educación que les haga posible cambiar su propio futuro y puedan salir de la pobreza y socorrer a otros. Para combatir la pobreza de valores que podemos encontrar en nuestra sociedad, tenemos que ayudarnos a salir del individualismo egoísta que nos sumerge en el consumismo compulsivo, que podría parecer que nos llena de alegría, pero que bien sabemos que es pasajera (Francisco, 2013, n. 197). La verdadera alegría nace de poner en práctica la misericordia con los demás, lo que implica la ayuda mutua y la búsqueda del bien común para que todos los que vivimos en este mundo podamos disfrutar de los mismos derechos.

\section{El carisma salesiano como propuesta de la espiritualidad de la alegría}

Don Bosco dedicó su vida a atender a los jóvenes, especialmente a los más pobres, que vivían en la calle y que eran explotados en trabajos en los que su vida corría peligro. Él les ofreció un ambiente donde podían educarse y sentirse seguros, como si fuese una gran familia. Este es el carisma de la familia salesiana. Pero ¿cuál es el carisma salesiano? San Juan Bosco basó toda su obra en dos grandes pilares: la eucaristía y María Auxiliadora, y fue a ellos a los que pidió que les ayudase para poder luchar por sus "chicos", como él los llamaba. Con sus acciones y su ejemplo, fue mostrando su carisma, el mismo que plasmó en la congregación que fundaría años más tarde y que hoy en día sigue trabajando en todo el mundo por la juventud. 
Cuando decimos espiritualidad salesiana, nos referimos a la espiritualidad propia de todas aquellas personas que dentro de un grupo reconocido comparten verdadero parentesco espiritual y una consanguinidad apostólica como herederos y portadores del espíritu y de la misión que el Espíritu Santo confió a Don Bosco para la vida de la Iglesia. El carisma salesiano se basa en la propuesta de santidad como una alegría profunda en lo cotidiano, es decir, que, sin importar lo que hagamos, hay que hacerlo con alegría; aun en los momentos difíciles debemos estar alegres porque somos amados por Dios y Él está siempre con nosotros. Don Bosco repetía constantemente: "Para nosotros la santidad consiste en estar siempre alegres". Partiendo del Cristo Resucitado, este optimismo se traduce en:

- Tener fe en la victoria del bien: para ello, hay que saber conectar con la cuerda sensible del corazón.

- Estar abiertos a los valores humanos: más que lamentarse, el salesiano capta los valores del mundo y trata de darles cauce adecuado ante la educación de la fe.

- Educar en las alegrías cotidianas: la educación trata de aprender a saborear con sencillez las múltiples alegrías humanas que Dios ha puesto en nuestro camino.

Además, otra de las características del carisma salesiano es la cordialidad y el ambiente familiar en que se desarrolla su labor basada en el sistema preventivo, apoyado en la razón, la religión y la amabilidad. Con ello busca dar confianza a los jóvenes para que disipen sus miedos y abran sus corazones para poder sembrar valores en ellos. Crear un espacio donde se pueda convivir en total libertad, seguridad y alegría. Todo esto lo podemos ver reflejado en los salesianos que hoy en día siguen luchando incansablemente por la salvación de las almas ( $D a$ mihi animas, coetera tolle) alrededor del mundo y que, confiando en María Auxiliadora, ponen cada día en práctica el ejemplo de Don Bosco.

\section{Conclusión}

La espiritualidad de la alegría es una de las formas más exigentes y difíciles que podemos presentar en esta vida, tal como normalmente funcionamos los seres humanos, porque, cuando hablamos de este asunto, no se trata de que uno programe su vida para vivir siempre alegre y en continua diversión. Se trata, más bien, de que uno organice su vida de manera que, en el ambiente en el que viva y entre las personas con quienes conviva, haga todo lo que esté a su alcance para 
que los demás se sientan bien, vivan en paz, convivan a gusto y, sobre todo, sean personas tan felices que la alegría se transparente a todas horas en sus rostros.

Asumir eso como proyecto de vida, he ahí lo que supone y exige la espiritualidad de la que aquí estamos hablando. Esto supone, en primer lugar, recordar la importancia de fortalecer, desde la infancia, la interioridad, que nos lleva a conocernos, a reconocer los dones que Dios nos ha regalado personalmente y también los que poseen los que me rodean, y que deben ser compartidos para que se multipliquen y hagamos crecer el Reino, que nos ayuda a hacer silencio para poder encontrarnos con aquel que nos ama primero. La relación con Él será la que nos llena de la alegría plena junto con el seguimiento y la vivencia de los valores del Evangelio.

Un valor que hay que fortalecer en nuestra sociedad es la misma vida social, que comienza en las familias, que nos enseña a vivir desde el amor que recibimos y que estamos llamados a dar a aquellos que nos rodean, a respetar y acoger las diferencias que hay entre todos, que nos posibilita crecer en el diálogo y en la búsqueda de soluciones a los problemas que se nos presentan a lo largo de la vida, que nos ayuda a crecer desde la libertad, y que por ello somos responsables de nuestras acciones.

Ese vivir en comunión nos ayudará a comprender la misma vida de la Iglesia, que nos pide vivir la comunión en la que, como los primeros discípulos, se comparte todo lo que se tiene y se vive con un mismo espíritu, unidos por la vivencia y la experiencia, y acogiendo las diferencias, por lo que nadie queda fuera o excluido. Desde el inicio del cristianismo ha sido el testimonio de los miembros de las Iglesias la mejor llamada para las personas que rodeaban a sus miembros. No podemos olvidar el cuidado, por parte de la comunidad cristiana, de las familias. En estos momentos, es una de las instituciones más frágiles de nuestra sociedad; por ello, se hace necesario favorecer la escucha entre sus miembros y también de las dificultades que viven en el día a día.

No debemos olvidar que desde el inicio del cristianismo hemos sido capaces de inculturar los valores del Evangelio. Por ello, se nos llama a buscar y aprovechar los valores que nos ofrece la sociedad, para desde ellos poder llegar a las personas más alejadas de la Iglesia, sin olvidar que todo lo que ofrece la sociedad no es válido, pues no nos ayuda a ser mejores personas. Somos llamados a usar los lenguajes actuales, los que usan los más jóvenes de nuestra sociedad, enseñando su buen uso. Puede pasarnos que al principio no los entendamos, pero los niños y los jóvenes son capaces, al ver que deseamos estar cerca de ellos, de ayudarnos a comprenderlos. 
También me parece importante la escucha de los niños y jóvenes, de sus inquietudes y necesidades; en muchos casos, ellos tienen una idea de Dios y de la Iglesia de la que debemos partir en la evangelización, y en algunos casos debemos reeducarla, pues no siempre es correcta. Esa escucha debe ser sin límite de tiempo, pues la persona que se siente escuchada se llega a sentir importante y por ello querida. Esa dedicación puede ayudar a descubrir todo el bien que hay en los miembros de la Iglesia, al mismo tiempo que se llega a conocer el amor que Dios nos tiene.

Un momento privilegiado para la escucha se nos presenta cuando las familias, los niños o los jóvenes se acercan a la parroquia para solicitar recibir un sacramento. Ese momento de catequesis es fundamental, pues, además de enseñarles cómo vive un cristiano, podemos ayudarlos a experimentar y con ello favorecer el encuentro con Cristo. Nuestros itinerarios de catequesis y educación en la fe deben favorecer realizar experiencias que muevan el corazón humano hacia el bien común a vivir los valores del Evangelio. En muchos momentos, debemos presentar y realizar actividades que desde el sentimiento muevan a la persona a descubrir la propia riqueza y cómo la riqueza de los demás la complementa, que juntos podemos construir un mundo mejor.

Necesitamos que nuestro mundo sea más humano, que busque vivir junto con los demás, que piense en todo aquello que nos une, solo así podremos ser felices y nuestra alegría se verá colmada. La espiritualidad de la alegría es seguramente la expresión más clara y más fuerte de lo que significa la "humanización de Dios". Lo que pasa es que, con demasiada frecuencia, anteponemos nuestra deshumanización a la incomprensible humanidad que se nos reveló en Jesús el Señor. En esto, si no nos equivocamos, radica el fondo del problema.

\section{Referencias}

Bravo Tisner, A. (2012). Meditaciones sobre la alegría cristiana. Salamanca, España: Sígueme.

Catecismo de la Iglesia Católica (1997). Bilbao: Asociación de Editores del Catecismo.

Centro Nacional Salesiano de Pastoral Juvenil (2014). Itinerario de educación en la fe: guía del animador. Madrid, España: Editorial CCS.

Francisco (2013). Exhortación apostólica Evangelii gaudium. Madrid, España: Edibesa.

Francisco (2015). Carta Encíclica Laudato si' sobre el cuidado de la casa común. Madrid, España: Edibesa. 
Francisco. (2016). Exhortación apostólica Amoris laetitia sobre el amor de la familia. Madrid, España: Palabra.

Gutiérrez Cuesta, K. y Rojano Martínez, J. (2016). Algunas claves pastorales del papa Francisco. Misión Joven, 56(477), 21-30. Recuperado de http://www.pastoraljuvenil.es/algunas-claves-pastorales-del-magisterio-de-francisco/

Hijas de María Auxiliadora (2016). Constituciones y reglamentos de las Hijas de María Auxiliadora. Madrid, España: Editorial CCS.

Léon-Dufour, X. (1973). Vocabulario de teología bíblica. Barcelona, España: Herder.

Moral de la Parte, J. (2014). Jóvenes: ciudadanos en la Iglesia, cristianos en el mundo. Misión Joven, 54(444-445), 47-57. Recuperado de http://www.pastoraljuvenil.es/ jovenes-ciudadanos-en-la-iglesia-cristianos-en-el-mundo/

Pablo VI (1975). Exhortación apostólica Gaudete in dominum sobre la alegría cristiana. Madrid, España: San Pablo. 